\title{
Research on Futures Arbitrage Based on Iron Ore Futures
}

\section{Yong Wang}

\author{
School of finance, Zhejiang University of Finance \& Economics, Hangzhou 310018, China \\ upcnku@163.com
}

\section{Keywords: Iron Ore Futures; Arbitrage Method; Arbitrage Strategy}

\begin{abstract}
Steel industry is one of the pillar industries of China's national economy, while the iron ore is the main raw material for smelting steel. China is rich in iron ore resources, but less in rich iron ore, which results in the difficulty and high cost of the use of iron ore. Therefore, the main source of China's iron ore relies on import, at the same time, China becomes the largest production and consumption country. This paper studies domestic and foreign achievements of futures arbitrage from aspects of arbitrage methods and arbitrage strategies, and classifies these literatures. We should consider the price volatility of iron ore futures and the long-term equilibrium relationship with the other relative futures.
\end{abstract}

\section{Introduction}

Our country mainly relies on imported iron ore, and iron ore imports in 2001 from 91.57 million tons to 952.72 million tons in 2015 , increased by nearly 10 times, which is the world's largest iron ore consumer and importer. The current iron ore price is determined by the annual iron ore trade negotiations between the main producers and the world's main suppliers of iron ore. In iron ore price negotiations, regardless of which the first iron and steel enterprise and supplier annual price my briefcase, it generally will be other global iron ore prices and iron and steel enterprises and suppliers, i.e. starting pricing power. So far, China has only received the initial price in 2006, which is very bad for the development of Chinese steel enterprises. Therefore, the Dalian commodity exchange launched iron ore futures in October 2013, hoping to strengthen the voice of China's iron ore futures in international pricing with the introduction of iron ore futures.

In addition to iron ore, coke and also closely linked to steel, $90 \%$ of coke production used in operation, and is mainly used for smelting steel, therefore, coke and steel is a typical upstream and downstream industry chain. Iron ore, coke and steel futures can realize the linkage of steel industry chain, which can help enterprises realize the "whole industry chain" hedging operation and enhance the enterprise's ability to resist risks. Therefore, research on the futures market arbitrage is bound to China's commodity futures investment enterprises to participate in important theoretical basis, also is the future and the practice of overseas investors in China's futures market game instructions. Therefore, this article about the steel industry chain across commodity arbitrage in the theoretical research, is beneficial supplement of the domestic steel industry chain across commodity expansion from arbitrage between the two kinds of futures arbitrage strategy research for iron ore, coke and rebar futures varieties across commodity arbitrage strategy research.

\section{Arbitrage Ways}

Existing futures arbitrage research mainly focuses on arbitrage and arbitrage strategy. Futures arbitrage is a trading activity that takes advantage of the price difference between the market or the contract and trades on the relevant market or contract. According to the existing arbitrage method, futures arbitrage can be divided into three categories: cross-stage arbitrage, cross-market arbitrage and cross-commodity arbitrage.

Cross-stage Arbitrage. Cross-term arbitrage is the act of trading profit by buying and selling futures contracts of different months of the same commodity in the trading market. Foreign scholars such as Klemkosky and Lee (1991) [1] had studied the trading data of standard \& poor's 500 index futures between 1983 and 1987, while Klemkosky and Lee examined the pricing biases for every 10 
minutes. The empirical results showed that even for arbitrageurs had biggest no-arbitrage interval, 5\% of the time also will fall in the absence of arbitrage pricing deviation interval, futures overestimate the frequency and degree of higher than undervalued. In addition, allowing for 10 minutes of trading delays, arbitrage was profitable for all types of arbitrageurs. John (2012) [2] in the United States listed CBOT soybean futures from 1913 to 1941, fluctuations in the price of soybean research found that soy obvious seasonal trend, thus realize soy inter-temporal arbitrage between the different contract.

Domestic scholars such as Weifeng Wang and Yang Liu (2007) [3] emulated the domestic csi 300 stock index futures market would be the study of inter-temporal arbitrage. The empirical results showed that the theoretical space of cross-phase arbitrage was quite obvious during the opening period of Shanghai and Shenzhen 300 index futures, and there were obvious arbitrage opportunities. Guijun Chen chose Dalian Commodity Exchange (2015) [4] produce soybean futures one main contract price data as the research object, to our country agricultural products futures arbitrage efficiency study, found that soybean between one part of the contract can be inter-temporal arbitrage.

Cross-market Arbitrage. Across the market arbitrage refers to in a market to buy (or sell) a particular delivery month of a commodity contract, at the same time in another market to sell (or buy) same goods of the same delivery month contracts and the trading behavior of profit. Foreign scholars, such as Perlin et al. (2014) [5] used probit model to carry out cross-market arbitrage research on European bond market. The empirical results showed that cross-market arbitrage was predictable.

Domestic scholars such as Zou Yan (2004) [6] from the perspective of physical delivery, uses the principle of no arbitrage, given buy London copper sell no-arbitrage condition of Shanghai copper futures, and in May 1995 to June 2002 to buy the three-month London three-month copper sell Shanghai copper has carried on the empirical test, has carried on the feasibility study to arbitrage across the market. Guiping Sun (2015) [7] through the method of before and after the event, the csi 300 index options from the Angle of risk-free arbitrage between the simulation and the csi 300 index futures markets across the market arbitrage efficiency for pioneering research. The empirical results showed that the simulation options in the options market boundary conditions across the market brought about by the arbitrage opportunity is very little, and on options on futures parity equation, did exist in theory of arbitrage opportunities across the market, and index options on the market as a whole had a strong market efficiency.

Cross-commodity Arbitrage. Across commodity arbitrage refers to the transactions in the market to buy a particular delivery month a commodity futures contracts, and sell the other same delivery month, interrelated commodity futures contracts and the trading behavior of profit. Foreign scholars such as Frank (1989) [8] proved oil when squeezing spreads on the high side by buying soybean futures selling soybean meal, soybean oil futures at the same time to lock the high press spreads to increase revenue and reduce risk. Ivanov (2011) [9] studied the intraday data of gold, silver and oil exchange traded funds and their respective commodity futures. The discovery of the availability of the ETF's price discovery function had been transferred to the gold and silver ETF market, while the price discovery function in the oil market remained largely in the futures market.

Domestic scholars such as Xiaomei Yin (2005) [10] statistical arbitrage analysis for soybean oil and palm oil. The empirical results showed that there is an arbitrage relationship between soybean oil and palm oil. Quan Gu and Xinghui Lei (2015) [11] were the research object of the main contract of soybean, soybean meal and soybean oil futures in big business. The results showed that the profit ability of the statistical arbitrage was not obvious, and the determination of transaction threshold had a strong correlation with transaction cost, transaction frequency and arbitrage effect.

\section{Arbitrage Strategies}

According to the existing research results, in terms of arbitrage strategy, there are two main categories: traditional mean return arbitrage strategy and neural network arbitrage strategy. The former focuses on the long-term balanced relationship between the relevant futures and the 
corresponding arbitrage strategies. The latter focuses on the short-term fluctuations that exist between the relevant futures and the corresponding arbitrage strategies based on fluctuations.

Traditional Mean Return Arbitrage Strategy. Mean reversion arbitrage method is through the measure of financial time series such as cointegration and error correction model (ECM), regression etc to analyze the long-standing relationship between commodity futures, design corresponding arbitrage strategy. Wahab (1994) [12] selected such as gold and silver and used closing price as the research object, using the method of co-integration and error correction model analysis, the relationship between the price of both moving average method was used to carry the cross between the two commodities. Domestic scholars such as Bin Dong (2005) [13] used ADF test and cointegration test on the effectiveness of the Shanghai futures exchange aluminum futures market has carried on the empirical research, found that the Shanghai aluminum futures market to weak type of effective, and aluminium exists cointegration relationship between futures and spot prices.

Neural Network Arbitrage Strategy. The strategy of neural network arbitrage is that it has a strong nonlinear fitting ability and is widely used in practical research. The neural network arbitrage strategy focuses on the research object's volatility, thus making arbitrage strategies. Haider et al. (2008) [14] used artificial neural network model to predict the oil futures market, and found that using artificial neural network to develop arbitrage strategy could help to improve the yield. Phoebe and David (2014) [15] using the RBF neural network, LM neural network model for soybean meal, soybean oil, soybean and its squeezing goods spread analysis predicted the short-term fluctuations, thinking that traders could according to the forward contracts affected the recent contract squeezing spreads profit carry this phenomenon. At present domestic scholars such as Haohua Xu and Haifeng $\mathrm{Gu}$ (2014) [16] respectively studied the application of neural network to carry method, and the main research of stock index futures and gold futures arbitrage strategy.

\section{Summary and Prospect}

Summary of Existing Iron Ore Futures Arbitrage. According to the existing research results of domestic and foreign arbitrage, the relevant achievements of futures arbitrage mainly exist in the following characteristics:

Research on futures arbitrage way is the main across goods carry on existing futures arbitrage, and mainly focused on the research of agricultural products futures arbitrage and crude oil and its derivatives, futures arbitrage, relatively few studies on metal futures arbitrage, and domestic academia focuses on coke and rebar across both commodity futures arbitrage research, lack of coke, iron ore, rebar futures the related research results of cross commodity futures arbitrage.

In the research of futures arbitrage strategy, early research mainly applies the traditional mean regression model method. This method mainly through econometric methods as cointegration and error correction model (ECM) regression model to analyze the target the long-standing relationship between futures and related futures, so as to realize the arbitrage strategy. The application of this method is very wide, and also has achieved a lot of results. However, the mean regression method values the long-term equilibrium relationship between different futures varieties, and ignores the price fluctuation mechanism between futures varieties.

More and more scholars began to apply the neural network model method to study the futures arbitrage strategy. The research direction in foreign scholars have a lot of achievements, such as Dunis (2013) [17] arbitrage strategy research has found that neural network can achieve better than the mean reversion arbitrage strategy can get results of arbitrage and the application of neural network model has considerable diversity. But domestic scholars use the neural network model to study the outcome of futures arbitrage strategy.

In addition, the sample data selected from relevant research results at home and abroad are mainly based on the closing price of trading day. This data selection method may lead to the failure to accurately reflect the price fluctuation of the day and the potential arbitrage opportunities. On the other hand, it could also lead to a more than one day of delay in the opening of the carry trade, resulting in a longer holding period and a loss of potential arbitrage opportunities.

Future Research and Outlook. Summarizing previous research results, this paper argues that 
there is still room for further improvement in the research of iron ore futures arbitrage. First of all, some research has focused on the long-term equilibrium relationship between study of commodity futures, and from there make effective arbitrage strategy of mutual relations, but ignore the one existing in the process of market volatility. Second, some research has focused on the use of different economic models to predict the trend of the futures price, according to the predicted price make effective arbitrage strategy, but ignored the goods in the process of a long-term equilibrium relationship between futures. Again, using the neural network model for domestic iron ore futures arbitrage strategy research is still rare, domestic scholars is necessary to invest more in the research direction of resources, intensify research. Finally, in the sample data selection, the trading day's closing price is the main one. In view of this, it is necessary to make the arbitrage strategy of selecting sample data from the high frequency data of the trading day. This will not only avoid the problem of long positions, but also increase returns.

\section{References}

[1] Klemkosky R C and Lee J H. The Intraday Expost and Exante and Profitability of Index Arbitrage. Journal of Futures Markets, 1991,11(3):291-311.

[2] William John. How to Profit From Commodity Futures Trading. Tianjin: Tianjin Academy of Social Sciences Press, 2012.128-144.

[3] W.F. Wang and Y. Liu. Cross-phase Arbitrage Research in Stock Index Futures. Financial Research, 200712:236-241. (In Chinese)

[4] G.J. Chen. Empirical Research on the Arbitrage Efficiency of Agricultural Products in China. Price Theory and Practice, 2015, 02:91-93. (In Chinese)

[5] Perlin M, Dufour A and Brooks C. The Determinants of a Cross Market Arbitrage Opportunity: Theory and Evidence for the European Bond Market. Annals of Finance, 2014, 10(3):457-480.

[6] Y. Zou, H.L. Liu and C.F. Wu. The Cross-market Arbitrage of Shanghai Copper and London Copper and Its Empirical Test. Application of System Engineering Theory, 2004, 02:142-146. (In Chinese)

[7] G.P. Sun. Research on the Effectiveness of the Cross-market Arbitrage of the csi 300 Index Option Simulation. Business Research, 2015, 10:54-63. (In Chinese)

[8] Frank S D, Irwin S H, Pfeiffer G H and Curtis C E. Further Evidence on Soybean Marketing Strategies: the Role of Options. North Central Journal of Agricultural Economics, 1989, 11(2):213-219.

[9] Ivanov S Y. The Influence of ETFs on the Price Discovery of Gold, Silver and oil. Journal of Economics \& Finance, 2011, 37(3):453-462.

[10] X.M. Yin, T. Sun and Z.D. Xu. The Feasibility Study of the Cross-commodity Arbitrage Between Palm Oil and Soybean Oil Futures Based on High Frequency Data. Rural Economy and Technology, 200808:84-86. (In Chinese)

[11] Q. Gu and X.H. Lei. Empirical Research on the Statistical Arbitrage of Soybean Futures Based on Co-integration. Statistics and Decision, 2015, 07:151-154. (In Chinese)

[12] Wagab, M, Cohn, R and Lashgari, M. The Gold-silver Spread: Integration, Cointegration, Predictability, and Ex-ante Arbitrage. Journal of Futures Markets, 1988, 8(2): 709-756.

[13] B. Dong, T. Zhu and Y.N. Qiu. The Empirical Study on the Effectiveness of Shanghai Aluminum Futures Market. Technical Economy, 2005, 12:66-69. (In Chinese)

[14] Haider I, Kulkarni S and Pan H. Forecasting Model for Crude Oil Prices Based on Artificial Neural Networks. In Proceeding of The International Conference on Intelligent Sensors, Sensor Networks and Information Processing(ISSNIP'08), 2008, 103-108.

[15] Phoebe S W and David E. Nonlinear Modeling Using Neural Networks for Trading the Soybean Complex. Procedia Computer Science, 2014, 36, 234-239.

[16] H.H. Xu and H.F. Gu. Short-term Price Forecasting Model of Stock Index Futures Research-BP Neural Network Model Based on Difference. Journal of Financial Teaching and Research, 2014, 3:27-32. (In Chinese)

[17] Dunis C L, Laws J, Middleton P W and Karathanasopoulos A. Trading and Hedging the 
Corn/Ethanol Crush Spread Using Time-varying Leverage and Nonlinear Models. The European Journal of Finance, 2013, 21(4):1-24. 